\title{
Dinamika Penanganan Penumpang Jamaah Umrah dan Haji plus oleh Perusahaan Wisata, Haji, Umrah (WHU) di Bandar Udara Soekarno-Hatta
}

\author{
Bambang Soekarsono $^{1}$, Ryan Firdiansyah ${ }^{2}$, IG.P.Willy Hermawan ${ }^{3}$ \\ ${ }^{1,2,3}$ Sekolah Tinggi Penerbangan A VIASI, Jakarta, Indonesia \\ e-mail: ryan@stp-aviasi.ac.id, b.soekarsono@gmail.com, willy.hermawan75@gmail.com
}

\begin{abstract}
The purpose of this study was to see and how much the benefits of tourism services, Hajj and Umrah (WHU) for pilgrims going to Umrah and Hajj plus, both data from tourist agencies, Hajj and Umrah (WHU) are displayed here to inform and become discussion material for further research as input in service industry and tourism management, Hajj and Umrah (WHU). The research method used in this study is descriptive research with a qualitative analysis approach, and using the results of informant interviews and secondary data reports the number of pilgrims of two tourism service companies, Hajj and Umrah (WHU) in Soekarno-Hatta airport, namely Avia Citra Dirgantara and WHU service company that does not want to mention its name. Secondary data provided from two tourism service companies, Hajj and Umrah (WHU) namely aeronautical imagery and other WHU companies that did not want to be named, the company's secondary data for aerospace imagery for two years taken from March to July 2017 totaled 11,710 pilgrims and rising in 2018 range from March to July 2018 to 16,980 worshipers, while data from other companies that start operating from January 2018, and get secondary data on the number of pilgrims from March to July 2019 with 11,065 worshipers.
\end{abstract}

From the two analysis data obtained from two WHU service companies the researchers concluded according to the purpose that the benefits of services and handling of tourism services, Hajj and Umrah services provided assistance to pilgrims plus umrah from the check-in process to the waiting room (airline's lounge). For further results from this study requires a further study

Keyword : Passenger Handling, Travel, Hajj and Umrah (WHU).

\section{PENDAHULUAN}

Transportasi udara adalah transportasi yang populer yang digunakan oleh penumpang di
Indonesia dan seluruh dunia, penggunaan transportasi udara saat ini membantu penumpang dalam proses mobilitas, perpindahan, dan menuju suatu tujuan atau rute 
ke suatu tempat atau domestik ataupun menuju ke negara lain. Pesawat udara membantu penumpang (masyarakat) dalam memenuhi kebutuhan setiap manusia dalam hal kesenangan dan liburan, karena merupakan penghubung dari suatu daerah wisata ke daerah lainnya yang terletak baik dalam negeri maupun luar negeri (Septiyani Putri Astuti, 2012). Maskapai penerbangan dalam negeri tumbuh pesat dengan melayani rute penerbangan baik rute dalam negeri maupun melayani rute internasional.

Maskapai dapat menangani pertumbuhan penumpang dengan meningkatkan frekuensi atau ukuran pesawat, yang mungkin memerlukan jumlah pergerakan pesawat yang berbeda. (K.Kolker et al, 2016). Banyak perusahaan maskapai penerbangan (airline) bermunculan dan berkembang seiring dengan meningkatnya mobilitas manusia dan permintaan atas jasa transportasi udara.

Keadaan ini, sudah tentu menimbulkan persaingan yang ketat antar perusahaan penerbangan Transportasi udara saat ini menjadi pilihan utama dalam melakukan perjalanan sehingga rute-rute yang dilayani oleh airline semakin meningkat (Miskul Firdaus dan Andi Nur Eviani, 2015).

Berdasarkan data BPS tahun 2012 total pergerakan pesawat domestik 717.435 dan pergerakan pesawat internasional 84.962, sedangkan pergerakan penumpang domestik
70.682.216 dan pergerakan penumpang internasional 11.749.073. (Gunawan, Rully Mediant, 2017). Penumpang sebagai pengguna jasa maskapai akan memilih maaskapai mana yang akan digunakan dalam mencapai tujuan. Penumpang adalah seseorang yang melakukan perjalanan dengan pesawat udara dan tidak terdaftar sebagai awak pesawat udara yang bersangkutan (Martono, 2007).

Berdasarkan jenisnya, penumpang dibagi menjadi 7 bagian, yaitu ; Jenis-jenis Penumpang pesawat udara dapat dibedakan sebagai berikut 1) Penumpang VVIP, VIP/CIP, adalah penumpang tertentu yang mempunyai fungsi dan kedudukan tinggi, misalnya pemimpin negara asing, menteri-menteri, Ketua MPR/DPR/DPA, dll; 2) Unaccompanied Minor (UM) adalah penumpang anak-anak yang bepergian sendiri tanpa didampingi oleh penumpang dewasa lainnya yang minimal berusia12 tahun (penerbangan international) dan 10 tahun (penerbangan domestik) yang sepenuhnya mampu mengurus dirinya sendiri sepanjang perjalanan; 3) Asylum Seeker/INAD inadmissable adalah penumpang yang bermaksud mendapatkan suaka atau menjadi imigran pada suatu negara tertentu secara illegal; tidak bisa diterima masuk suatu negara; 4) Penumpang yang bermasalah dengan keimigrasian (Deportee) adalah yang berkaitan dengan penyalahgunaan dokumen-dokumen 
perjalanan penumpang internasional, baik dokumen yang dipalsukan (tidak valid), di salah gunakan, maupun dokumen-dokumen yang tidak lengkap; 5) Groups,adalah para penumpang yang berangkat bersama dengan jumlah paling tidak 9 orang (tidak termasuk infant); 6) Passenger Requiring Assistance adalah penumpang penyandang cacat dan mereka yang membutuhkan atau meminta bantuan dalam bepergian; 7) Passenger Requiring Medical Clearance adalah penumpang perlu surat keterangan dokter yaitu penumpang yang tampaknya memiliki gejala penyakit atau kondisi yang dapat menimbulkan ancaman langsung terhadap kesehatan dan keselamatan orang lain dalam penerbangan.

Penumpang udara menggunakan beberapa fungsi sistem informasi penumpang selama perjalanan mereka. Manajemen informasi yang tidak memadai dapat menimbulkan ketidakpastian. (E. Nagy, C. Csisz, 2017). Penumpang dari tingkat ekonomi yang berlainan menaiki pesawat udara milik maskapai, sehingga memerlukan suatu penanganan dan dilayaninya penumpang sehingga terbantukan dalan proses sebelum menuju pesawat. Salah satu jenis penumpang yang setiap saat ada dan menggunakan transportasi udara adalah penumpang Wisata, Haji Plus dan Umrah, yang paling banyak adalah jamaah umrah yang berasal dari berbagai kalangan dan tingkat ekonomi dengan menggunakan jasa tour travel yang berbeda dalam memberikan kelas dan jenis umrah yang di jual kepada jamaah. Penumpang jamaah umrah yang menuju bandar udara secara berkelompok /group dengan tujuan ke tanah suci, Saudi Arabia untuk menunaikan Ibadah Umrah yang rata-rata harinya adalah 9 (sembilan). Penanganan dan pelayanan penumpang jenis umrah ini belum secara maksimal ditangani oleh penyedia jasa ground handling yang ada.

Penanganan penumpang umrah saat ini yang ada di semua bandara Internasional di Indonesia belum maksimal dan belum teroganisir dengan baik dan tertata. Pemberian ijin dari otoritas bandara internasional Soekarno-Hatta kepada pemilik modal yang ingin membuka jasa pelayanan dengan nama Wisata, Haji dan Umrah (WHU). Saat ini pemberian fasilitas jasa penanganan bagi penumpang WHU ini baru ada di bandar udara internasional Soekarno-Hatta, dimana penumpang umrah dan haji plus terbantukan dan dilayani dari saat keberangkatan, mulai dari penerimaan jamaah di bandara, check-in ticket dan bagasi group umrah, mengarahkan ke imigrasi sampai mengantar ke ruang tunggu. Pada saat kedatangan,menjemput jamaah di terminal kedatangan internasional sampai membantu pengambilan bagasi dan air zam-zam 
dan mengarahkan keluar terminal untuk disamput oleh agen travelnya.

Ibadah umrah dan bukan merukan suatu kewajiban bagi muslim, tetapi ada beberapa tipe jamaah umrah yang menjadi penumpang umrah yang akan berangkat ke tanah suci antara lain moderat (ingin dilayani, memiliki pengetahuan dan biaya tidak menjadikan masalah) dan mediun (tipe penumpang ini kebelikan dari penumpang jamaah umrah dimana mereka untuk umrah rela menabung dan menjual sesuatu di daerahnya agar supaya bisa umrah dan tidak memiliki ilmu pengetahuan yang berkaitan dengan penerbangan). Ibadah umrah ini dapat dilaksanakan setiap saat, Ibadah umrah sama halnya dengan perjalanan yang mana berbeda dengan ibadah haji yang hanya dilaksanakan pada tanggal tertentu pada bulan haji (khusnul, khotimah, 2014). Ada tiga jenis tugas utama yang banyak memperoleh perhatian pemerintah tetapi sekaligus menjadi sasaran kritik masyarakat luas setiap menjelang dan berakhirnya penyelenggaraan ibadah haji dan umrah setiap tahun yaitu (1). pelayanan, (2). pembinaan, dan (3). Perlindungan (M. Shidqon Prabowo, 2011).

Jasa Pelayanan penumpang untuk umrah dan haji plus dibulan-bulan umrah dan haji plus khusus di bulan haji yang diberikan oleh otoritas bandara Soekarno-Hatta saat ini sudah ada beberapa perusahaan yang diberikan ijin, pelayanan penumpang umrah dan haji plus yang saat ini baru ada di bandara internasional Soekarno-Hatta membuat penumpang merasa terlayani dan tertangani. Oleh sebab itu dalam penelitian ini ingin mengungkap jasa pelayanan penumpang WHU ini ada di bandara soekarnohatta, dan dipercaya oleh agen travel yang menggunakan jasa WHU di bandar udara Soekarno-Hatta. Tujuan dari penelitian ini adalah melihat dan seberapa besar manfaat dengan adanya jasa wisata, haji, dan umrah (WHU) bagi jamaah yang akan berpergian umrah dan haji plus, kedua data dari agen wisata, haji dan umrah (WHU) ditampilkan disini untuk memberitahukan dan menjadi bahan diskusi bagi penelitian selanjutnya sebagai masukan dalam industi jasa pelayanan dan penanganan wisata, haji dan umrah (WHU).

\section{GROUND HANDLING}

Ground handling berasal dari kata "ground" dan "handling". Ground artinya darat atau di darat, yang dalam hal ini di bandara (airport). Handling berasal dari kata hand atau handle yang artinya tangan atau tangani. To handle berarti menangani, melakukan suatu pekerjaan tertentu dengan penuh kesadaran. Handling berarti penanganan atau pelayanan (service to service, sehingga pada banyak kesempatan kita sering menjumpai pemakaian kata "Ground Service". Dalam banyak kasus, 
kita juga sering menemukan kata "Ground Operation”. Baik “Ground Handling”, “Ground Service", "Ground Operation", maupun "Airport Service", pada dasarnya mengandung maksud dan pengertian yang sama, yaitu merujuk kepada "suatu aktivitas perusahaan penerbangan yang berkaitan dengan penanganan atau pelayanan terhadap para penumpang berikut bagasinya, kargo, pos, peralatan pembantu pergerakan pesawat di darat dan pesawat terbang itu sendiri selama berada di bandara, untuk keberangkatan (departure) maupun untuk kedatangan atau ketibaan (arrival)”. (Abdul Majid, Suharto dan Warpani, Eko Probo., 2009).

Secara sederhana, "Ground Handling" atau "Tata Operasi Darat" adalah pengetahuan dan keterampilan tentang penanganan pesawat di apron, penanganan penumpang dan bagasinya di terminal dan kargo, serta pos di cargo area. Pelayanan adalah suatu kegiatan atau urutan kegiatan yang terjadi dalam interaksi langsung antara seseorang dengan orang lain atau mesin secara fisik, dan menyediakan kepuasan pelanggan. Sedangkan penumpang adalah seorang atau lebih, baik dewasa, anakanak, maupun bayi yang memiliki perjanjian antara pihak pengangkut yang dituangkan ke dalam bentuk tiket perjalanan untuk menggunakan transportasi baik darat, laut maupun udara. Dalam transportasi udara khususnya airlines mengklasifikasikan.

Dalam transportasi udara khususnya airlines dalam penanganan operasional pesawat di darat akan kerjasama dengan pihak ground handling yang perjanjiannya sesuai dengan AHM 810 - IATA Standard Ground Handling Agreement, yang versinya adalah SGHA Versi 1998, 2004, 2008 dan 2013, sebagai berikut : AHM 810 - IATA Standard Ground Handling Agreement - 35th Edition Valid 1st January 2015, terdiri dari delapan section antara lain ; 1) Standard Ground Handling Agreement (SGHA), Version 2013 Main Agreeme Annex A (semua data pekerjaan handling yang bisa dikerjasamakan), Annex B (data pekerjaan handling yang dipilih maskapai). Annex A (delapan Sections), Section 1- Managing functios, Section 2- Passenger Services, Section 3- Ramp Services, Section 4- Load Control, Communications and Flight Operations, Section 5- Cargo and mail Warehouse Services, Section 6- Support Services, Section 7- Security, dan Section 8-Aircraft Maintenance.

Dalam hal ini yang ada hubungannya dengan WHU adalah hanya Section 2 Passenger Services, dimana pihak ground handling mengerjakan Section 2 sesuai yang dipilih dan disetujui pihak airline yang tertampung didalam Annex B, yang beberapa pekerjaan itu diantaranya adalah check-in 
penumpang dan barang serta check document. Sedangkan pekerjaan pihak WHU adalah membantu dalam proses passenger handling untuk kenyamanan dan kepuasan penumpang serta kecepatan dalam proses keberangkatan para jamaah umroh agar penerbangan bisa berangkat tepat waktu, yaitu mulai proses check-in group umroh dan bagasinya, mengarahkan ke Imigrasi dan mengantar sampai boarding gate, sedangkan untuk kedatangan adalah menjemput di terminal kedatangan dan membantu pengambilan bagasi serta membantu koordinasi dengan pihak Lost and Found airline jikalau ada bagasi yang tidak ditemukan atau tertinggal.

\section{Ruang Lingkup Ground Handling}

Ruang lingkup atau batasan pekerjaan "Ground

Handling", yaitu pada fase atau tahap:

\section{Pre-Flight}

Kegiatan penanganan terhadap penumpang berikut bagasinya dan kargo serta pos dan pesawat sebelum keberangkatan (di bandara asal origin station).

\section{Post Flight}

Kegiatan penanganan terhadap penumpang beserta bagasinya dan kargo serta pos dan pesawat setelah penerbangan (di bandara tujuan/destination). Atau dengan kata lain penanganan penumpang dan pesawat selama berada di bandara. Secara teknis operasional, aktivitas "Ground Handling" dimulai pada saat pesawat "taxi" (parking stand), mesin pesawat sudah dimatikan, roda pesawat sudah diganjal (block on), dan pintu pesawat sudah dibuka (open the door), serta para penumpang sudah dipersilahkan untuk turun atau keluar dari pesawat. Maka, pada saat itu para staf udara sudah memiliki kewenangan untuk mengambil alih pekerjaan dari "Pilot In Command (PIC)" beserta cabin crew-nya. Dengan demikian, fase ini kita namakan "Arrival Handling". Dan sebaliknya, kegiatan atau pekerjaan orang-orang darat berakhir ketika pesawat siap-siap untuk lepas landas, yaitu pada saat pintu pesawat ditutup, mesin dihidupkan, dan ganjal roda pesawat sudah dilepas (block off). Tanggung jawab pada fase ini (in-flight) berada di 3 tangan "Pilot In Command" beserta para awak cabinnya. Fase ini dikenal dengan istilah "Departure Handling”.

Objek yang ditangani oleh ground staff pada intinya meliputi: penumpang (pax), barang bawaan penumpang (baggage), barang kiriman (cargo), benda-benda pos (mail), ramp, dan aircraft. Sebagai sebuah proses 
penanganan, maka muncul istilah: passenger handling, baggage handling, cargo and mail handling, dan ramp handling.

Di mana baik ruang lingkup maupun objek kegiatan tersebut harus mengacu kepada aturan yang telah ditetapkan oleh "IATA Airport Handling Manual, 810 Annex A", yang telah menetapkan sebanyak 14 section pelayanan standar atau 14 kegiatan.

\section{Tujuan Ground Handling}

Ground handling mempunyai tujuan atau targettarget/sasaran-sasaran yang ingin dicapai, yakni:

\section{Flight Safety}

2. On Time Performance

3. Customer Satisfaction

4. Reliability

\section{Pengertian Passenger Handling}

Passenger handling adalah proses penanganan dan pelayanan terhadap penumpang pada saat di terminal bandar udara keberangkatan maupun kedatangan. Kegiatan passenger handling terdiri dari beberapa unit yaitu check-in counter, boarding gate, customer service dan lost and found. Check-in counter merupakan tempat dimana penumpang memperoleh boarding pass dan menimbang bagasinya untuk diberi label dan dimasukan ke dalam pesawat. Pada saat check-in, penumpang tersebut harus menyerahkan tiket dan identitas dirinya kepada petugas check-in counter untuk diperiksa.

Setelah check-in dan memperoleh boarding pass, penumpang tersebut diperbolehkan untuk masuk ruang tunggu (boarding gate). Pada saat masuk ke boarding gate, boarding pass penumpang akan diperiksa oleh petugas boarding gate. Pemeriksaan dilakukan agar petugas bisa mendata kembali berapa banyak penumpang yang sudah masuk ke boarding gate. Jika pesawat sudah boarding, petugas boarding gate akan mengarahkan penumpang untuk masuk ke dalam pesawat sesuai urutan.

Urutan penumpang yang naik pesawat yang pertama yaitu penumpang sakit atau disable passenger, dan special passenger, setelah itu penumpang yang membawa bayi dan anak kecil, lalu penumpang ekonomi dengan nomer urut kursi di belakang. Setelah itu yang executive penumpang yang mempunyai green seat.

Di terminal kedatangan, penumpang yang membawa bagasi dapat mengambil bagasinya di conveyor belt. Sebelum penumpang tersebut keluar dari area terminal kedatangan, label bagasinya akan diperiksa dan dicocokan oleh petugas apakah sesuai dengan nomer bagasi yang dibawa oleh penumpang. Jika penumpang kehilangan bagasinya atau terdapat kerusakan pada bagasinya, penumpang 
tersebut harus melaporkan kejadian tersebut kepada petugas lost and found. Petugas lost and found akan menangani jika terjadi masalah terhadap bagasi penumpang yang hilang maupun rusak.

Kegiatan baggage handling dan cargo handling adalah kegiatan penanganan terhadap bagasi dan kargo yang akan diberangkatkan dengan pesawat maupun bagasi dan kargo yang datang di bandara tujuan. Aircraft handling yaitu pelayanan menangani pesawat saat berada di darat. Kegiatan aircraft handling yaitu meliputi pengisian bahan bakar (refueling), perawatan pesawat (maintenance) pengisian air bersih, menjaga kebersihan pesawat udara, bongkar muat bagasi dan kargo, mempersiapkan peralatan untuk kegiatan turun dan naik penumpang dari dan ke pesawat. Semua kegiatan tersebut dilakukan di area apron.

\section{Pengertian Ibadah Umrah dan Haji}

Ibadah umrah adalah suatu ibadah yang dilakukan secara sengaja ke Baitullah untuk melakukan ibadah tawaf dan sa'i. Hukum ibadah umrah menurut ahli fiqih dari madhab Shafi'i dan Hanabilah, adalah wajib sebagaimana halnya ibadah haji, karena kedua ibadah tersebut diperintahkan Allah SWT untuk disempurnakan seperti yang ditegaskan dalam surat al-Baqarah [2]: 196.

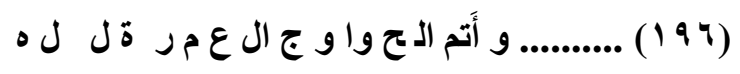

"Dan sempurnakanlah ibadah haji dan umrah karena Allah.”.

Ibadah umrah merupakan ibadah yang dianjurkan oleh Allah, ibadah umrah hanya diwajibkan sekali dalam seumur hidup. Melonjaknya peminat umrah disebabkan karena antrian panjang dari ibadah haji, sehingga banyak dari masyarakat yang lebih memilih melaksanakan ibadah umrah,disebabkan karena beberapa hal diantaranya, ibadah umrah terkesan lebih mudah, praktis, tanpa menunggu antrian panjang dan bisa dilakukan kapan saja tanpa harus menunggu bulan Dzulhijjah.

\section{Wisata, Haji dan Umrah (WHU)}

Penanganan dan pelayanan jasa dibidang wisata, haji dan umrah (WHU) ini tumbuh kembang di bandar udara soekarno-hatta dalam dua tahun terakhir. Pemberian ijin kepada perusahaan yang memiliki ijin beroperasi ground handling dari Kementrian Perhubungan.

Jamaah umrah dan haji plus terbantukan dalam persiapan pemberangkatan, check in counter, pengurusan imigrasi, sampai dengan naik ke dalam pesawat.

\section{Jumlah Jamaah}

Direktur Bina Umrah dan Haji Khusus Kementerian Agama (Kemenag) M Arfi Hatim mengatakan,tiap tahun tren jamaah umrah di Indonesia mengalami peningkatan cukup signifikan. Jumlah visa umrah yang telah dikeluarkan untuk Indonesia pada 2016 
mencapai 699.000 visa.Jumlah ini meningkat 7,2 persen dari 2015 .

Dari data tersebut, Indonesia berada di peringkat ketiga untuk jumlah jemaah umrah terbanyak, di samping Mesir dengan 1,3 juta orang (peringkat pertama) dan Pakistan dengan 991.300 orang (peringkat kedua). (Reni Rohmawati, 2017).

\section{Metode Penelitian}

Penelitian ini adalah penelitian deskriptif dengan pendekatan analisis kualitatif, dan menggunakan hasil wawancara informasn sebagai data penelitian. Pemilihan desain penelitian didasarkan atas beberapa pertimbangan, diantaranya : penulisan semikualitatif digunakan untuk mendeskripkan latar belakang interaksi yang komplek, bukti-bukti lapangan yang akan memberikan pemahaman yang tepat, dan hasil data penumpang yang dilayani oleh peusahaan jasa wisata, haji dan umrah (WHU).

Penelitian ini dilaksanakan di beberapa perusahaan jasa WHU dari bulan Maret sampai dengan Juli 2018. Data yang didapatkan berupa data kuantitatif pelayanan dan penanganan jamaah haji plus dan umrah dari dua perusahaan yang melayani jasa Wisata, Haji dan Umrah yang beroperasi di bandar udara soekarno-hatta, selain itu data kuantitatif dijabarkan dalam bentuk narasi ditambahkan dengan hasil wawancara ringkas dari informan dua perusahaan yang peneliti observasi.

\section{Hasil dan Pembahasan}

Penumpang umrah dan haji plus sebelum ada jasa WHU ini belum terkordinir dengan baik dalam penanganan dan pelayanan, masih dilakukan oleh pihak ground handling maskapai. Dua tahun terakhir menurut dari informan kami dan pemilik jasa WHU yang ditemui oleh kami bertiga selaku peneliti coba mendalami dengan adanya informasi dari informan yang mengunakan jasa WHU yang ada di Bandar Udara Soekarno-Hatta.

Melihat ke objek penelitian yang kami lakukan bahwa dengan hasil diskusi kami dengan wakil dari dua jasa WHU memberikan informasi, bahwa ijin perusahaan mereka dalam menjalankan jasa WHU ini adalah ijin pelaksanaan ground handling, dan ijin jasa WHU berasal dari pihak Angkasa Pura II (Persero) Bandar Udara Soekarno-Hatta.

Data kuantitatif yang didapatkan dari jasa WHU pertama yaitu Avia citra dirgantara tahun 2017 digambarkan sebagai berikut ;

Data Jumlah Penumpang Umrah dan Haji plus yang menggunakan Jasa WHU Tahun 2017 di Bandar Udara Soekarno-Hatta

\begin{tabular}{l|c}
\hline \multicolumn{1}{c|}{ Tahun } & $\begin{array}{c}\text { Jumlah Passenger } \\
\text { Total }\end{array}$ \\
\hline 2017 & 11.710 Jamaah \\
\hline \multicolumn{2}{l}{ Sumber data : Avia Citra Dirgantara tahun 2017 }
\end{tabular}


Tahun 2017 merupakan awal perusahaan Avia Citra Dirgantara mendapatkan ijin operasi dari PT. Angkasa Pura II (Persero) bandar udara soekarno-hatta melayani dan menangani penumpang dan barang yang dibawa oleh jamaah sebanyak 11.710 dari berbagai macam travel agent umrah dan haji plus yang mengadakan perjalanan dari bulan Maret sampai dengan bulan Juli 2018.

Terlihat bahwa jumlah jamaah melalui travel agent umrah dan haji plus menggunakan penanganan dan pelayan jasa WHU ini adalah untuk membantu dan memudahkan penumpang yang akan menjalankan ibadah dan juga melayani juga kepulangan untuk jamaah umrah dan haji plus. Data tahun 2017 dan hasil diskusi dengan salah satu karwayan Human Resources Depertment Avia Citra Dirgantara.

Perusahaan memiliki strategi untuk mencari calon penumpang dengan cara menghubungi dan mengajukan penawaran kepada travel agent umrah dan haji plus yang memiliki jamaah dan akan berangkat.

Data jumlah penumpang tahun 2018 yang didapatkan akan jamaah yang dibantu dan ditangani oleh perusahaan jasa WHU ini sebagai berikut ;

Data Jumlah Penumpang Umrah dan Haji plus yang menggunakan Jasa WHU Tahun 2018 di Bandar Udara Soekarno-Hatta

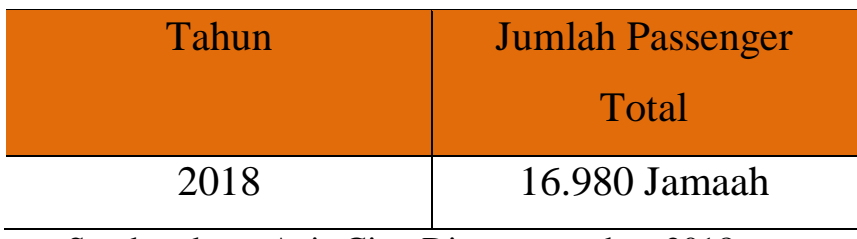

Sumber data : Avia Citra Dirgantara tahun 2018

Pada tahun 2018 dari bulan Maret sampai dengan Juli 2018 perusahaan melayani jamaah sebanyak 16.394, ada peningkatan sebesar $45 \%$ dari tahun 2017. Data ini memang data selesai sampai akhir tahun namun melihat data dari tahun 2017 dengan tahun 2018 maka minat dari travel agent untuk menggunakan jasa WHU mengalami peningkatan. Data tambahan dari hasil diskusi dengan bagian HRD perusahaan mengenai pelayanan dan penanganan penumpang ini mendapatkan suatu jawaban untuk mendukung data kuantitatif di atas dalam bentuk jawaban sebagai berikut ; 1) ijin yang diberikan untuk usaha WHU ini dari PT. Angkasa Pura II (Persero) kepada perusahaan; 2) kesulitan awal bisnis WHU ini adalah sosialisasi dan menawarkan kepada travel agen haji dan umrah agar jamaahnya dilayani oleh perusahaan; 3) sumber daya manusia yang terlibat di awal bisnis ini ; 4) setelah berjalan dan travel agen merasakan dampaknya untuk jamaah terbantukan mulai dari check in counter, boarding pass, pemeriksaaan dokumen imigrasi, sampai pada ruang tunggu.

Selain itu peneliti mendapatkan data dari perusahaan lain yang sama yang melayani dan membantu penanganan jamaah ini. Namun 
dalam observasi ke perusahaan, pihak perusahaan tidak ingin nama perusahaannya di tampilkan sehingga data yang kami dapatkan dari hasil diskusi dengan salah satu pemilik saham di bisnis WHU ini adalah benar dan bisa dipertanggungjawabkan.

Data kuantitatif di dapatkan dari pemilik perusahaan data dari Maret sampai dengan Juli tahun 2018, peneliti hanya coba menampilkan data tersebut untuk melihat jasa WHU yang ada di bandar udara soekarno-hatta ;

Data Jumlah Penumpang Umrah dan Haji plus yang menggunakan Jasa WHU Tahun 2018 di Bandar Udara Soekarno-Hatta

\begin{tabular}{c|c}
\hline Tahun & $\begin{array}{c}\text { Jumlah Passenger } \\
\text { Total }\end{array}$ \\
\hline 2018 & 11.065 Jamaah \\
\hline
\end{tabular}

Sumber 'PT X' jasa WHU di Bandar Udara SoekarnoHatta

Hasil data yang kami dapatkan tahun 2018 ini memang perusahaan ini baru beroperasi dari tahun 2018, dengan total 11.065 jamaah dari berbagai macam travel agent yang dilayani seperti Altrama, Ventour, Rihlah Tour (Kalimantan), Mujahadah Haji dan Umrah, Barrata Travel, Wildan Raudah Madinah, dan Ventour.

Perolehan data hasil observasi yang digambarkan dalam penelitian ini mengenai bisnis WHU ini didukung dengan hasil wawancara dengan salah satu pemilik saham perusahaan WHU yang beroperasi di bandar udara soekarno-hatta sebagai berikut ; 1) usaha WHU ini merupakan usaha yang memiliki prospek yang bagus sehingga kami ikut dalam membuka bisnis ini; 2) tujuan WHU ini adalah untuk membantu jamaah haji plus dan umrah sehingga mereka bisa terbantukan mulai dari check in sampai menuju ruang tunggu penumpang milik maskapai; 3) penyiapan sarana dan prasarana yang tidak sulit untuk membantu jamaah.

Dalam mendukung penanganan dan pelayanan penumpang peneliti coba menampilkan data perusahaan WHU didukung dengan sarana, prosedur, dan sumber daya manusia yang nantinya akan digunakan atau dijalankan oleh perusahaan WHU tidak jauh berbeda dan akan dijabarkan sebagai berikut ; Sarana yang dimiliki untuk mendukung untuk menangani dan melayani penumpang umrah dari dua perusahaan yang ditanyakan dari hasil diskusi yang digunakan untuk membantu pelayanan jamaah umrah seperti troli untuk barang, dan tas penyimpanan paspor milik penumpang, telepon seluler milik setiap karyawan, komputer dan meja rapat. Sumber daya manusia yang bekerja di perusahaan jasa WHU ada sepuluh karyawan dengan keahlian yang dimiliki dari tingkat pendidikan SMA sampai dengan Diploma. 
Prosedur Sumber Daya Dalam Bekerja Prosedur kerja dimulai dari membagikan jadwal penerbangan dan kedatangan. Pembagian dilakukan pada malam hari sebelum hari $\mathrm{H}$, selanjutnya supervisor akan membagikan jadwal dan nama-nama staf yang akan menangani penerbangan keberangatan atau kedatangan untuk keesokan harinya sehingga staf tidak berkumpul di suatu titik untuk mengangani beberapa keberangkatan atau kedatangan.

Dari data hasil observasi yang didapatkan melalui data sekunder yang dimiliki perusahaan maka dukungan untuk melayani dan menangani penumpang sudah cukup memadai dengan catatan dari hasil pengamatan dari peneliti bahwa kecakapan sumber daya manusia dalam tegur sapa dalam menghadapi penumpang masih belum terlihat, mungkin dalam penelitian selanjutnya bisa diulas, untuk sarana dan prasarana, dan prosedur sudah berjalan sesuai menurut hasil pengamatan peneliti.

\section{Simpulan}

Hasil yang didapatkan dari hasil penelitian ini dapat disimpulkan sesuai dengan tujuan penelitian ini bahwa dengan adanya bisnis jasa Wisata, Haji dan Umrah (WHU) yang dimana dalam pendirian dan perijinan yang dikeluarkan oleh PT. Angkasa Pura II (Persero) dilihat dari data kuantitatif dari perusahaan jasa Wisata Haji dan Umrah ini memberikan bantuan penanganan dan pelayanan kepada jamaah umrah dengan data dari Maret sampai dengan Juli 2018 mendapatkan hasil data kuantitatif jumlah jamaah yang menggunakan jasa WHU ini sebanyak 11-710 jamaah dan pada tahun 2018 dari bulan Maret sampai dengan Juli 2018 dimana data kuantitatif jumlah jamaah mengalami peningkatan sebesar $45 \%$ sebesar 16.980 jamaah.

Hasil wawancara dari dua perusahaan yaitu avia citra dirgantara dan satu perusahaan jasa WHU yang tidak ingin disebutkan namanya memperoleh hasil wawancara dan diskusi dari perusahaan avia citra dirgantara yaitu 1) ijin yang diberikan untuk usaha WHU ini dari PT. Angkasa Pura II (Persero) kepada perusahaan; 2) kesulitan awal bisnis WHU ini adalah sosialisasi dan menawarkan kepada travel agen haji dan umrah agar jamaahnya dilayani oleh perusahaan; 3) sumber daya manusia yang terlibat di awal bisnis ini ; 4) setelah berjalan dan travel agen merasakan dampaknya untuk jamaah terbantukan mulai dari check in counter, boarding pass, pemeriksaaan dokumen imigrasi, sampai pada ruang tunggu. Sedangkan hasil wawancara dari salah satu perusahaan yang menjalankan bisnis jasa WHU yang sama adalah sebagai berikut ; 1) usaha WHU ini merupakan usaha yang memiliki prospek yang bagus 
sehingga kami ikut dalam membuka bisnis ini; 2) tujuan WHU ini adalah untuk membantu jamaah haji plus dan umrah sehingga mereka bisa terbantukan mulai dari check in sampai menuju ruang tunggu penumpang milik maskapai; 3) penyiapan sarana dan prasarana yang tidak sulit untuk membantu jamaah.

Dari dua data analisis yang didapatkan dari dua perusahaan jasa WHU peneliti menyimpulkan sesuai dengan tujuan bahwa kemanfaatan pelayanan dan penanganan jasa Wisata, Haji dan Umrah ini memberikan bantuan kepada jamaah haji plus dan umrah dari proses check in sampai dengan ruang tunggu (lounge milik maskapai). Untuk hasil lebih lanjut dari penelitian ini memerlukan suatu penelitian yang lebih lanjut.

\section{DAFTAR PUSTAKA}

Abdul Majid, Suharto dan Warpani, Eko Probo.

$\begin{array}{lrr}\text { (2009). } & \text { Ground } & \text { Handling } \\ \text { Manajemen } & \text { Pelayanan } & \text { Darat } \\ \text { Perusahaan } & \text { Penerbangan. } & \text { Jakarta: } \\ \text { Rajawali Press. } & & \end{array}$

Angela, 2009, Penanganan Penumpang Pada

Perusahaan Ground Handling, Laporan

Tugas Akhir, Sekolah Tinggi Teknologi

Kedirgantaraan, Yogyakarta.

Arikunto, Suharsimi. 2006. Prosedur penelitian suatu Pendekatan Praktik. Jakarta; PT. Asdi Mahasatya.
E. Nagy, C. Csisz, Model of an integrated air passenger information system and its adaptation to Budapest Airport, Journal of Air Transport Management (2017), 19.

Eko Widianto,"Peserta Umrah Melonjak dua kali selama Ramadan”, dalam http://www.tempo.co/read/news

Januari 2013).

Firdaus Miskul dan Eviani Andi Nur, Jurnal Manajemen Bisnis Transportasi Dan Logistik, Vol.1 No 2 Januari 2015

Fiqih Awlawiya, Prioritas Aantara Ibadah Umrah Lebih Dari Sekali dan Menuntut Ilmu Dalam Perspektif Elit NU Surabaya, Nasfa Alif Diana NIM. F02411015, Pascasarjana Universitas Islam Negeri Surabaya 2015.

Gunawan, Rully MediantoTanggal terbit 2017/1/16 JurnalProsiding Seminar Nasional Re TII Deskripsi.

K. Kolker et al. / Journal of Air Transport Management xxx (2016) 1-8.

Lestari, 2008, Keselamatan Penerbangan ditinjau dari segi penumpang dan barang, Tugas Akhir, Sekolah Tinggi Teknologi.

Martono. 2007. Kamus Hukum dan Regulasi Penerbangan. Jakarta; PT. Raja Grafindo. 
Mulyono, Taufik., 2007, Aspek Keselamatan

Penerbangan di Daerah Lingkungan

Kerja Bandar Udara, Tugas Akhir

Sekolah Tinggi Teknologi.

Rahmat Ritonga dan Zainuddin, Fiqih Ibadah (Jakarta: Gaya Media Pratama, 1997), 210.

Shidqon Prabowo, Persaingan Usaha yang Sehat Dalam Penyelenggaraan haji di Indonesia (Prespektif Hukum Persaingan Usaha dan Anti Monopoli), Prosiding Seminar Ilmiah Nasional Komputer dan Sistem Intelijen (KOMMIT 2014) Vol. 8 Oktober 2014 Universitas Gunadarma, Depok - 14 - 15 Oktober 2014 ISSN : 2302-3740 Al-Buqha, Mustafa, PokokPokok Ajaran Islam Syariah Arbain Nawawiyah, Rabbani Express, Jakarta, 2012.

Sibuea, Iriani. 2009. Peranan Pramugari Terhadap Keselamatan Penerbangan Menurut Pandangan Penumpang Garuda Indonesia Di Bandara Internasional Adisutjipto Yogyakarta. Laporan Tugas Akhir, Sekolah Tinggi Teknologi Kedirgantaraan, Yogyakarta.

Umar, C., 2004. Pengaruh Kualitas Pelayanan Terhadap Minat Beli Ulang Penumpang Sriwijaya Air Di Bandara Kolonial
Medan. Medan : Tesis, Sekolah Pascasarjana Universitas Suma.

Zainudin bin Abd al-Aziz al-Malibari, Fath alMuin, Juz 2 (Beirut: Dar al-Fikr), 280.

Data hasil Dialog Umrah 2018 SINDO Weekly yang digelar di Rumah Sakit Haji Jakarta, Pondok Gede, Jakarta Timur, Kamis (15/3/2018).

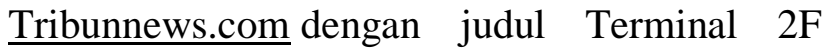
Bandara Soekarno-Hatta Akan Jadi TerminalUmrah, http://www.tribunnews. com/regional/2017/06/11/terminal2fbandara-soekarno-hatta-akan-jaditerminal-umrah. 